\title{
Influence of Cumulative Feed Intake during Early and Mid-Lactation on Luteinizing Hormone Secretion and Weaning-to-Estrus Interval in Primiparous Sows
}

\author{
Yuzo KOKETSU \\ Department of Clinical and Population Sciences, University of Minnesota, St. Paul 55108, U.S.A.
}

(Received 5 June 1998/Accepted 2 December 1998)

ABSTRACT. Twelve pregnant gilts were assigned to a completely randomized block design with two treatments in two blocks $(2$ farrowing
groups). The treatments were a feeding amount of $6 \mathrm{~kg}$ or $2 \mathrm{~kg} /$ day provided during lactation. The lactation diet contained $18.6 \% \mathrm{crude}$
protein, $1.0 \%$ lysine, and $3.27 \mathrm{Mcal} / \mathrm{kg}$ metabolizable energy (as-fed basis). Litters were weaned at 2100 on day 21 after farrowing.
Blood samples for luteinizing hormone $(\mathrm{LH})$ measurements were taken at 15 -min intervals for $8 \mathrm{hr}$ on day 12 of lactation, and samples for
glucose and insulin were collected at $1-\mathrm{hr}$ intervals for $3 \mathrm{hr}$ on day 12 . The effects of feed intake treatments on LH pulse frequencies $(2.9$
vs 0.7$)$ and insulin concentrations $(15.0 \mathrm{vs} 8.9 \mathrm{IU} / \mathrm{mL})$ were found $(\mathrm{P}<0.05)$ on day 12 of lactation. In regression analysis, greater
cumulative feed intake from 1 to 12 days was associated with higher insulin concentrations $(\mathrm{P}=0.04)$, greater LH pulse frequencies
( $\mathrm{P}=0.01)$ on day 12 of lactation, and shorter weaning-to-estrus intervals $(\mathrm{WEI})(\mathrm{P}=0.03)$. Furthermore, an association between insulin
concentrations and LH pulse frequencies was found on day 12 of lactation $(\mathrm{P}=0.01)$. Using regression models for weaning-to-estrus
interval, when each cumulative feed intake from 4 to 21 days was used as an independent variable, the $\mathrm{R}^{2}$ values increased from 0.24 to
0.37. These results suggest that feed intake during early and mid-lactation influences LH secretion as early as day 12 after farrowing, and
is associated with shorter WEI. This research also indicates that feed intake from 4 to 12 days of lactation is more important than that
during the first few days after farrowing.-KEY woRDs: cumulative feed intake, lactation, reproduction efficiency, sow. J. Vet. Med. Sci. 61(42): 325-329, 1999

Greater feed intake during lactation improves reproductive performance such as weaning-to-first-service interval and litter weight at weaning [9]. Feed intake during early and mid-lactation is suggested to be more important to improve weaning-to-first-service interval than that during late or the entire lactation [10], while low feed intake during any single week of lactation results in a prolonged weaningto-estrus interval (WEI) [7]. However, pork producers tend to restrict feed intake during early lactation because they are concerned about a feed intake drop during mid-lactation if sows are fed too much during the first 4 days after farrowing [8]. A question has arisen how early producers can restrict feed intake during early lactation to avoid a feed intake drop and to keep WEI within a normal range.

Luteinizing hormone ( $\mathrm{LH})$ is a key hormone which connects nutrition to reproduction, and is a primary factor in resuming estrus after weaning [5, 7]. The positive effects of energy intake during lactation on LH secretion at days 14 and 21 of lactation have been found [7]. Sows observed WEI within 7 days had greater LH pulse frequency and higher insulin concentrations than those with WEI $>7$ days [7]. In previous research, the regulation of estrogen receptors by insulin [17] and enhancement of LH release by insulin [1] have been reported. Furthermore, insulin receptors were found in the pituitary [12] and ovary [11]. Therefore, we hypothesized that the association between lactation feed intake and WEI is mediated by LH release with circulating levels of insulin and (or) glucose. However, few researchers have reported the effects of cumulative feed intake during early to mid-lactation on LH secretion, insulin concentrations and WEI. The objectives in this study were
1) to quantitatively evaluate the effects of cumulative feed intake from days 1 to 12 after farrowing on $\mathrm{LH}$ characteristics, and circulating levels of glucose and insulin on day 12 and WEI, and 2) to observe changes of the strength of associations between each cumulative feed intake from days 1 to 21 of 3 week-lactation and WEI by regression analysis.

\section{MATERIALS AND METHODS}

The research protocol was approved by the Institutional Animal Care and Use Committee of the University of Minnesota (No. 9311043). The estrous cycles of 12 Landrace $\mathrm{x}$ Yorkshire gilts in two breeding groups were synchronized by the daily oral administration of $15 \mathrm{mg} / \mathrm{gilt}$ of allyl-trenbolone (Regumate, Roussel-UCLAF, Paris, France) for 14 days. Gilts were artificially inseminated with pooled semen from boars at the first estrus following the feeding of allyl-trenbolone. These 12 pregnant gilts were assigned to a completely randomized block design with two treatments in two blocks ( 2 farrowing groups). The treatment was an amount of feed offered during lactation, 6 $\mathrm{kg} /$ day (FF) or $2 \mathrm{~kg}$ /day (low feed intake). The feed intake in the FF group was assumed to be close to $a d$ lib feeding for hourly feeders to fill a certain amount of feed. Primiparous sows farrowed during the summer were not expected to consume more than $6 \mathrm{~kg}$ of feed/day. The number of sows assigned into FF and low feed intake treatments were 8 and 4 sows, respectively. Regression analysis using actual feed intake during lactation was preplanned to be used in data analysis as well as analyses for a 
randomized complete block design. Varied feed intake in the FF treatment and low feed intake $(2 \mathrm{~kg})$ was intended to provide a wide variation in feed intake for use in regression analysis. Therefore, more gilts in the FF treatment were made to expect more variation in order to enhance regression analysis.

Sows farrowed at $368 \pm 1.3$ (SE) days of age with an average of postfarrowing body weight and backfat thickness of $173.1 \pm 2.5$ (SE) $\mathrm{kg}$ and $19.3 \pm 0.8$ (SE) mm, respectively. After farrowing in June and July in 1995, sows were fed their daily diet in 24 hourly meals equally delivered by an electronic feeder to minimize daily fluctuations in circulating levels of glucose and insulin. After weaning, sows received a $2 \mathrm{~kg} /$ day of a $14 \% \mathrm{CP}(0.64 \%$ lysine $)$ corn-soybean meal gestation diet.

Sows were fitted at least 4 days prior to blood sampling with indwelling jugular vein cannulas without anesthesia [2]. The lactation diet contained $18.6 \%$ crude protein, $1.0 \%$ lysine, and $3.27 \mathrm{Mcal} / \mathrm{kg}$ metabolizable energy (as-fed basis). All vitamins and minerals in the diet were $>125 \%$ of estimated requirements [14]. Feed not consumed was weighed daily to determine actual feed intake. Litters were adjusted within 2 days of lactation to nine pigs per sow. Sow body weights, backfat thickness, and litter weights were measured on days 0,12 and 21 of lactation. Day 12 was arbitrarily chosen as a day of mid-lactation. Sow backfat thicknesses (6 $\mathrm{cm}$ off midline at the 10th rib) were determined after farrowing by a amplitude-depth ultrasound machine (Lean-meater, Renco Corp., Minneapolis, MN). Litters were weaned at 2,100 on day 21 after farrowing. Sows were provided with the same amount of the diet on day 1 after weaning as they were fed during lactation. Sows were monitored for estrus once daily in the presence of a boar until 35 days after weaning or until estrus was detected.

Blood sample collection and processing: Blood samples were collected from sows at one day prior to weaning. Blood samples for $\mathrm{LH}$ analyses were collected at $15-\mathrm{min}$ intervals for $8 \mathrm{hr}$ from 1,300 to 2,100 on day 12 after farrowing. Blood samples for glucose and insulin were collected at 1-hr intervals for $3 \mathrm{hr}$ from 1,300 to 1,600 when LH samples were taken. Blood samples for glucose were immediately ejected into tubes containing $\mathrm{NaF}$ and centrifuged at $1,520 \times \mathrm{g}$ for $20 \mathrm{~min}$, then plasma was collected. Serum samples for insulin and LH were collected into clot activating culture tubes (Becton Dickinson Co., Rutherford, NJ). All samples were stored at $-20^{\circ} \mathrm{C}$ until they were analyzed.

A commercial colorimetric kit based upon the glucose oxidase method (Sigma Chemical, St. Louis, MO) was used for glucose analysis as we previously reported [7]. The interassay $\mathrm{CV}$ of glucose for one plasma pool measured in 9 assays was $7.4 \%$. The intra-assay CV of glucose for the reference sera measured four times in one assay was $1.2 \%$. Concentrations of insulin were measured using a solid phase RIA [6]. The intra-assay CV of insulin for the reference sera measured five times in one assay was $4.2 \%$. The interassay $\mathrm{CV}$ of insulin for the reference sera measured in
2 assays was $1.4 \%$.

Serum LH concentrations were measured using a heterologous double antibody RIA [4]. Antiporcine LH serum (GDN No. 566) was used at an initial dilution of 1:16,000. Purified ovine LH (LER 783-3) was radioiodinated with ${ }^{125} \mathrm{I}$ (New England Nuclear, Boston, MA) in the presence of chloramine T (Sigma Chemical, St. Louis, MO). Results were expressed relative to purified porcine LH (LER 566). Each serum sample was assayed in duplicate aliquots of $200 \mathrm{ml}$. The assay sensitivity, defined as $90 \%$ of total binding, was $0.30 \mathrm{ng} / \mathrm{ml}$. The intra-assay CV for low and high LH reference sera were 9.1 and $4.4 \%$, respectively. The interassay $\mathrm{CV}$ for low and high $\mathrm{LH}$ pools were 11.2 and $8.8 \%$, respectively. Pulse frequency of $\mathrm{LH}$ secretion was determined using a peak-detection program for microcomputers [18]. Two points for the nadir and two points for the peak with a $5 \%$ false positive rate were used to detect pulses. Mean LH concentration was also calculated as the average of serum LH concentrations in 33 collected blood samples per sow.

Statistical analysis: The data were analyzed first as a completely randomized block design using the GLM procedures of SAS [15]. No differences were found between the two blocks. Also, simple regression analyses were used to quantitatively evaluate the associations between cumulative feed intake, concentrations of glucose, insulin and mean LH, LH pulse frequency, and WEI in the GLM procedure of SAS. Furthermore, to investigate the effects of lactation stage from 1 to 21 days on WEI, 21 regression models were performed on each stage to predict WEI using each day's cumulative feed intake and daily feed intake. Normality of the residuals from all regression models was confirmed using the rankit plot test.

\section{RESULTS}

On day 12 of lactation, sow body weight loss, LH pulse frequency, and insulin concentrations were influenced $(\mathrm{P}<0.05)$ by feed intake treatment (Table 1$)$.

Using regression analyses, greater cumulative feed intake from days 1 to 12 was associated with greater LH frequency at day 12 of lactation $(\mathrm{P}=0.01)$, higher insulin concentration $(\mathrm{P}=0.04)$ on day 12 and shorter WEI $(\mathrm{P}=0.03)$ (Table 2$)$. For each one $\mathrm{kg}$ increase of cumulative feed intake from 1 to 12 days of lactation, WEI decreased 0.36 days.

In simple regression analysis, greater LH pulse frequency on day $12(\mathrm{P}=0.01)$ was associated with shorter WEI. The regression coefficient and the $\mathrm{R}^{2}$ value of the model were -2.50 and 0.52 , respectively. Furthermore, greater concentrations of insulin were associated with greater $\mathrm{LH}$ pulse frequency on day 12 of lactation $(\mathrm{P}=0.01)$. The regression coefficient and the $R^{2}$ value were 0.18 and 0.47 , respectively. However, the association between insulin concentrations and WEI was not significant $(\mathrm{P}=0.09)$. No associations between concentrations of mean $\mathrm{LH}$ and insulin were found $(\mathrm{P}>0.2)$. Glucose concentrations were also not associated with LH pulse frequency and mean $\mathrm{LH}$ 
Table 1. The effects of lactation feed intake treatments (FF vs Low) on key measurements

\begin{tabular}{|c|c|c|c|c|}
\hline Trait & FFa) & Low ${ }^{\text {a) }}$ & $\mathrm{RMSE}^{\mathrm{b})}$ & $P$-value \\
\hline No. of sows & 8 & 4 & - & - \\
\hline \multicolumn{5}{|l|}{ Cumulative feed intake, $\mathrm{kg}$} \\
\hline 1 to 12 days & 37.7 & 21.7 & 3.46 & $<0.01$ \\
\hline 13 to 21 days & 44.3 & 18.0 & 5.13 & $<0.01$ \\
\hline \multicolumn{5}{|l|}{ Weight loss, $\mathrm{kg}$} \\
\hline 1 to 12 days & 7.6 & 23.2 & 3.09 & $<0.01$ \\
\hline 13 to 21 days & 5.7 & 17.0 & 3.27 & $<0.01$ \\
\hline \multicolumn{5}{|l|}{ Backfat loss, mm } \\
\hline 1 to 12 days & 1.8 & 2.8 & 1.06 & 0.14 \\
\hline 13 to 21 days & 1.5 & 3.2 & 1.05 & 0.01 \\
\hline \multicolumn{5}{|l|}{ Litter weight gain, $\mathrm{kg}$} \\
\hline 1 to 12 days & 17.4 & 17.9 & 4.40 & 0.85 \\
\hline 13 to 21 days & 26.3 & 23.0 & 2.62 & 0.07 \\
\hline Weaning-to-estrus interval, days & 7.4 & 13.5 & 3.92 & 0.03 \\
\hline Mean LH concentration, $n \mathrm{~g} / \mathrm{ml}$ on day 12 & 0.44 & 0.36 & 0.10 & 0.21 \\
\hline LH pulse frequency/8 hr on day 12 & 2.9 & 0.70 & 0.68 & $<0.01$ \\
\hline Glucose, $\mathrm{mg} / \mathrm{d} l$ on day 12 & 8.7 & 80.5 & 7.14 & 0.67 \\
\hline Insulin, IU/m $l$ on day 12 & 15.0 & 8.9 & 4.51 & 0.04 \\
\hline
\end{tabular}

a) Sows were provided 6 (FF) or 2 (Low) $\mathrm{kg} / \mathrm{day}$.

b) $\mathrm{RMSE}=$ Root mean square error. The standard error of mean would equal the root MSE/root $n$.

Table 2. Regression coefficients, partial R2 and p-values of cumulative feed intake from days 1 to 12 on reproductive performance, and concentrations of insulin, glucose, mean LH, and LH pulse frequency on day 12 of lactation

\begin{tabular}{lrrrc}
\hline Dependent variable & $\begin{array}{c}\text { Regression } \\
\text { coefficient } \pm \mathrm{SE}^{\mathrm{a})}\end{array}$ & $\mathrm{R}^{2, \mathrm{~b})}$ & P-value & Intercept \\
\hline Sow body weight loss, kg & $-0.97 \pm 0.12$ & 0.81 & $<0.01$ & 43 \\
Sow backfat loss, mm & $-0.07 \pm 0.03$ & 0.32 & 0.03 & 4.5 \\
Litter weight gain, $\mathrm{kg}$ & $0.01 \pm 0.20$ & 0.00 & 0.97 & 17 \\
Mean LH concentration, $n \mathrm{~g} / \mathrm{m} l$ & $0.01 \pm 0.04$ & 0.08 & 0.35 & 0.3 \\
LH pulse frequency/8 hr & $0.12 \pm 0.04$ & 0.47 & 0.01 & -1.7 \\
Glucose concentration, $\mathrm{mg} / \mathrm{d} l$ & $0.08 \pm 0.25$ & 0.01 & 0.75 & 81 \\
Insulin concentration, $\mu \mathrm{IU} / \mathrm{m} l$ & $0.36 \pm 0.17$ & 0.28 & 0.04 & 1.6 \\
Weaning-to-estrus interval, days & $-0.36 \pm 0.15$ & 0.37 & 0.03 & 20.3 \\
\hline
\end{tabular}

a) Regression coefficient indicates changes in the dependent variable associated with each $1 \mathrm{~kg}$ increase in cumulative feed intake from days 1 to 12 after farrowing. The SE indicates SE of estimate.

b) $\mathrm{R}^{2}$ indicates the proportion of variation in the dependent variable that can be explained by cumulative feed intake from days 1 to 12 after farrowing.

concentrations $(\mathrm{P}>0.2)$.

In 21 regression analyses for WEI, the changes of $\mathrm{R}^{2}$, the strength of the associations between cumulative feed intake and WEI, are shown from days 1 to 12 in Fig. 1. The independent variable of interest is each cumulative feed intake from 1 to 21 days of lactation. As cumulative feed intake increased from 1 to 21 days, the values of $\mathrm{R}^{2}$ increased from 0.02 to 0.37 . From 3 to 4 days after farrowing, the $\mathrm{R}^{2}$ values increased from 0.09 to 0.24 (see Fig. 1). In contrast to cumulative feed intake, the effects of each daily feed intake on WEI were not significant $(\mathrm{P}>0.2)$.

\section{DISCUSSION}

The difference in cumulative feed intake between the treatments was only $16 \mathrm{~kg}$ on day 12 , but it affected sow body weight loss, LH pulse frequency and insulin concentrations on day 12 of lactation, and WEI. Combined with the data in the two feed intake treatments (actual average feed intake: 1.9 vs $3.9 \mathrm{~kg} /$ day), we used regression analyses to quantify the association between measurements. The regression analyses indicate that increasing cumulative feed intake by one $\mathrm{kg}$ decreases backfat loss by $0.7 \mathrm{~mm}$, and increases insulin concentration by $0.36 \mu \mathrm{IU} / \mathrm{m} l$ and $\mathrm{LH}$ 


\section{$\mathrm{R}^{2}$}

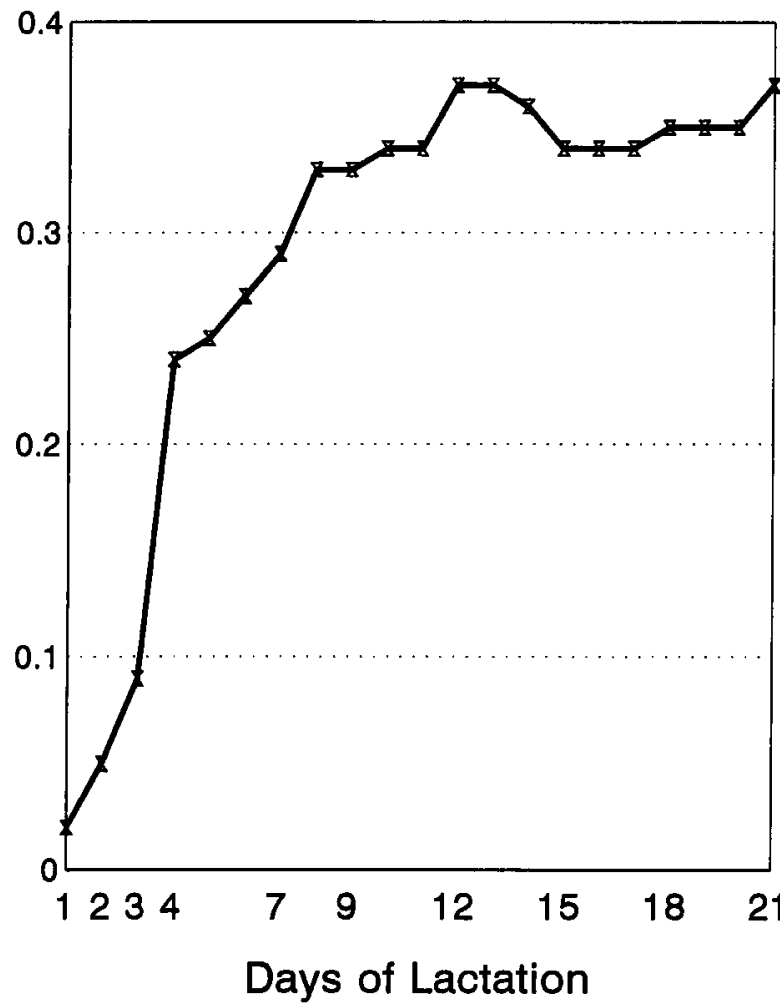

Fig. 1. Changes of the strength (R2) of the associations between cumulative feed intake during lactation from 1 to 21 days and weaning-to-estrus interval

pulse frequencies by 0.12 on day 12 of lactation, and decreases WEI by 0.36 days. The cumulative feed intake from 1 to 12 days also explains the substantial variation of 37 and $47 \%$ in WEI and LH pulse frequency on day 12 of lactation, respectively. These results suggest that feed intake during early and mid-lactation is important to shorten WEI. Previous studies suggested that increased feed or energy intake stimulates LH release in blood and resumption of estrus cycles [3, 7].

We could not detect the treatment difference in mean $\mathrm{LH}$ concentrations. This is probably because LH release during mid-lactation (12 days) is low (0.3 to $0.5 \mathrm{ng} / \mathrm{ml})$ [16], and it is close to our assay sensitivity, $0.30 \mathrm{ng} / \mathrm{ml}$.

Our research suggests that feed intake during early and mid-lactation of 3-week lactation increases $\mathrm{LH}$ pulse frequency as early as day 12 after farrowing, and is associated with shorter WEI. We previously reported that low feed intake during any single week of lactation increased WEI [7]. Thus, high feed intake during lactation should be maintained until weaning to prevent prolonged WEI.

Insulin concentrations are affected by the feed intake treatments. Insulin concentrations may be affected by milk production and body reserve mobilization as well as carbohydrate digestion, because insulin is a key hormone that regulates metabolism of carbohydrates and fat [13].
Furthermore, our regression analysis reveals an association between LH pulse frequency and insulin concentrations during mid-lactation. These associations between WEI, LH pulse frequency, insulin concentrations and cumulative feed intake during mid-lactation imply that the effect of nutrition on the relation between WEI and LH secretion are mediated, at least in part, through circulating levels of insulin.

In contrast to insulin, circulating levels of glucose were not affected by feed intake treatment, although levels of glucose are promptly increased by carbohydrate consumption [13]. Our feed intake is relatively low due to the experiment period, June and July. Relatively low feed intake in both treatments during blood sampling from 1300 to 1600 may have caused low glucose concentrations.

Cumulative feed intake from 4 to 21 days of lactation can explain the 24 to $37 \%$ variation in WEI, while cumulative feed intake from 1 to 3 days can explain no more than $10 \%$. This result suggests that feed intake from 4 to 21 days during lactation is more important to improve WEI than that during the first few days after farrowing. However, this result does not imply that days 1 to 3 of lactation are not important, because the information of cumulative feed intake on days $>4$ included daily feed intake from 1 to 3 days of lactation.

Feed intake on any single day of lactation was not significant to predict WEI due, in part, to the large day-today variations of feed intake. Thus, there is no single important day during lactation. Probably, cumulative feed intake is a good tool for producers to measure lactation feed intake to improve WEI rather than a day-by-day amount of feed during lactation.

ACKNOWLEDGMENTS. This research has been supported in part by the Minnesota Agricultural Experiment Station. We acknowledge Dr. L. E. Reichert, Albany Medical College, for supplying purified LH (LER 1374A and LER 786-3), Dr. G. D. Niswender, Colorado State University, for supplying antiporcine LH serum, Dr. V. L. King for her statistical consultation, Mr. S. Strain, Dr. M. Lorschy and Dr. A. Sower, and Mr. K. Rozeboom for their technical assistance.

\section{REFERENCES}

1. Adashi, E. Y., Hseuh A.J. W. and Yen S. S. C. 1981. Insulin enhancement of luteinizing hormone and follicle stimulating hormone by cultured pituitary cell. Endocrinology 108: 14411449.

2. Almond, G. W. and Dial, G. D. 1990. Steroid hormone and luteinizing hormone concentrations in the anestrus sow. Can. J. Vet. Res. 54: 209-214.

3. Armstrong, J. D. and Britt, J. H. 1987. Nutritionally-induced anestrus in gilts: Metabolic and endocrine changes associated with cessation and resumption of estrus cycles. J. Anim. Sci. 65: 508-523.

4. Dial, G. D., Dial, O. K., Bevier, G. W., Glenn, S. D. and Dzuik, P. J. 1983. Estrous behavior and circadian discharge of luteinizing hormone in the prepubertal gilt in response to 
exogenous estrogen. Biol. Reprod. 29: 1047-1056.

5. King, R. H. and Martin, G. B. 1989. Relationships between protein intake during lactation, LH levels and oestrus activity in first-litter sows. Anim. Reprod. Sci. 19: 283-292.

6. Knudson, B. J. 1990. Influence of Bioenergetics upon Metabolite Levels, Body Composition and Reproductive Performance of Female Swine. Ph.D. dissertation, University of Minnesota, St. Paul.

7. Koketsu, Y., Dial, G. D., Pettigrew, J. E., Marsh, W. E. and King, V. L. 1996a. Influence of imposed feed intake patterns during lactation on reproductive performance, circulating levels of glucose, insulin and luteinizing hormone in primiparous sows. J. Anim. Sci. 74: 1036-1046.

8. Koketsu, Y., Dial, G. D., Pettigrew, J. E., Marsh, W. E. and King, V. L. 1996b. Characterization of feed intake patterns during lactation in commercial swine herds. J. Anim. Sci. 74: 1202-1210.

9. Koketsu, Y., Dial, G. D., Pettigrew, J. E. and King, V. L. 1996c. Feed intake during lactation and subsequent reproductive performance of sows. J. Anim. Sci. 74: 2875-2884.

10. Koketsu, Y., Dial, G. D., Pettigrew, J. E. and King V. L. 1997. Influence of feed intake during individual weeks of lactation on reproductive performance of sows. Livest. Prod. Sci. 49: 217-225.

11. Ladenheim, R. G., Tesone, M. and Charreau, E. H. 1984. Insulin action and characterization of insulin receptors in rat luteal cells. Endocrinology 115: 752-756.

12. Lowe, Jr., W. L., Body, M.F.T., Clarke, D. W., Raizada, M. K., Hart, C. and LeRoith, D. 1986. Development of brain insulin receptors: structural and functional studies of insulin receptors from whole brain and primary cell cultures. Endocrinology 119: 25-35.

13. Murray, R. K., Mayes, P. A., Granner, D. K. and Rodwell, V. W. 1990. Harper's Biochemistry. (27th ed.). Appleton \& Lange. London. UK.

14. NRC. 1988. Nutrient Requirements of Domestic Animals, No. 2. Nutrient Requirements of Swine. Ninth revised ed. National Academy of Sciences - National Research Council, Washington, D.C.

15. SAS. 1988. SAS/Stat User's Guide. Statistical Analysis System Inst. Inc., Cary, NC.

16. Sesti, L.A.C. and Britt, J. H. 1993. Influence of stage of lactation, exogenous luteinizing hormone-releasing hormone, and suckling on estrus, positive feedback of luteinizing hormone, and ovulation in sows treated with estrogen. J. Anim. Sci. 71: 989-998.

17. Siegel, L. I. and Wade, G. N.. 1979. Insulin withdrawal impaired sexual receptivity and retention of bria cell nuclear estrogen receptors in diabetic rats. Neuroendo. 29: 200-206.

18. Veldhuis, J. D. and Johnson, M. L. 1986. Cluster analysis: a simple, versatile, and robust algorithm for endocrine pulse detection. Am. J. Physiol. 250: E486-493. 